MaŁgorZata Stasińska (autor korespondencyjny), Zofia Sotek, Instytut Nauk o Morzu i Środowisku, Uniwersytet Szczeciński, ul. Mickiewicza 16, 70-383 Szczecin, Polska; e-mail: malgorzata.stasinska@usz.edu.pl; zofia.sotek@usz.edu.pl

PATRyCJa RAdKe, Instytut Biologii, Uniwersytet Szczecinski, ul. Waska 13, 71-415 Szczecin, Polska; e-mail: patrycjaradke7@gmail.com

Wptynęło: 18.07.2020 r.; przyjęto do druku: 09.11.2020 r.

DOI: https://doi.org/10.35535/ffgp-2020-0025

\title{
Trichia sordida (Trichiaceae) - nowy dla Polski i Karpat gatunek śluzowca przyśnieżnego znaleziony w Tatrach
}

Śluzowce są mało poznaną grupą organizmów grzybopodobnych, należącą do królestwa Amoebozoa (ADL i in. 2019) i obejmującą około 1000 gatunków (RONIKIER \& HALAMSKI 2018). Charakteryzuje je skomplikowany cykl rozwojowy, którego głównym stadium wegetatywnym jest wielojądrowa mobilna masa protoplazmy nazywana śluźnią (plazmodium) (MARTIN \& AleXOPOUlus 1969). Po pewnym czasie życia w glebie, śluźnia wypełza na powierzchnię i przechodzi transformację, której efektem jest wytworzenie zarodni wypełnionych masą zarodników (KELLER i in. 2017). Śluzowce są organizmami kosmopolitycznymi (EvERHART \& KELLER 2008). Najczęściej spotykane są w lasach klimatu umiarkowanego, jednak zdolne są do opanowywania różnych środowisk, często o skrajnych warunkach siedliskowych, takich jak pustynie czy strefy na granicy topniejącego śniegu w górach (LiU i in. 2015).

Jedną z grup szczególnie interesujących z ekologicznego i ewolucyjnego punktu widzenia są śluzowce przyśnieżne związane z wąskim spektrum warunków środowiskowych panujących na przedpolu topniejącej zimowej pokrywy śniegu. Śluzowce przyśnieżne występują głównie na obszarach o charakterze górskim, gdzie gruba pokrywa śniegu zalega przez długi okres czasu i stopniowo topnieje wiosną i wczesnym latem. Na obszarze Polski gatunki należące do tej grupy podawane były głównie z Tatr, Gorców oraz - rzadziej - z innych części Beskidów (Drozdowicz 1988; Komorowska \& Drozdowicz 1996; RoniKIER i in. 2008; BochyneK \& DROZDOWICZ 2012; JANIK \& RonikiER 2016). W Tatrach odnotowano dotychczas dziesięć gatunków śluzowców przyśnieżnych: Diderma alpinum (Meyl.) Meyl., D. fallax (Rostaf.) E. Sheld., Lamproderma argenteobrunneum A. Ronikier, Lado \& Mar. Mey., L. sauteri Rostaf., Lepidoderma carestianum (Rabenh.) Rostaf., Meriderma carestiae (Ces. \& de Not.) Mar. Mey. \& Poulain, M. echinulatum (Meyl.) Mar. Mey. \& Poulain, M. spinulosporum ad. int., Physarum albescens Ellis ex T. Macbr. oraz Trichia alpina (R. E. Fr.) Meyl. (Drozdowicz 1988, 1995; Komorowska \& Drozdowicz 1996; Ronikier i in. 2010; JANIK \& RONIKIER 2016).

Rodzaj Trichia skupia gatunki charakteryzujące się jasną barwą zarodników i włośnią mającą postać wolnych nici (sprężyc) ornamentowanych spiralnymi zgrubieniami (wężownicami). Z Polski znanych było 14 gatunków z tego rodzaju (DrozDowicz i in. 2003), z których tylko jeden, Trichia alpina, jest gatunkiem przyśnieżnym (DrozDowicz 1988, 
RONIKIER i in. 2008). Oprócz T. alpina do gatunków związanych z obszarami górskimi i siedliskami przyśnieżnymi należą nie odnotowane dotychczas w Polsce T. sordida Johannesen oraz niedawno opisana z Alp T. nivicola Kuhnt (KuHNT 2019).

Trichia sordida to gatunek występujący na półkuli północnej i południowej. Na półkuli północnej znany jest z Europy, Ameryki Północnej i Azji (Japonia) (PoulAIN i in. 2011), jednak nie jest częsty. W Europie podawany był między innymi z Norwegii, skąd został opisany (Johannesen 1984), z gór Hiszpanii (Illana i in. 1993; SÁNCHEZ i in. 1997, 2002; LADO i in. 2005; LADO \& RoNIKIER 2008) oraz z Alp (MEYLAN 1921; Singer i in. 2001; KUHNT 2006; MEYER 2010). W ostatnim czasie gatunek został również znaleziony w Andach (Ameryka Południowa), gdzie jest jednym z częstszych gatunków z rzędu Trichiales, występujących w tamtejszych zbiorowiskach śluzowców przyśnieżnych (RoNIKIER i in. 2020).

W trakcie badań terenowych prowadzonych w Tatrzańskim Parku Narodowym wiosną 2020 r. w masywie Ciemniaka (Czerwone Wierchy) znaleziono dwa okazy Trichia sordida. Stanowisko znajduje się w lesie świerkowym, około 20 m na północny zachód od Polany Upłaz, na wysokości 1299 m n.p.m. (49¹5'05,0'N, 1952'46,4"E) (Ryc. 1, 2A). Dwa okazy (Ron 1031, KRAM M-1935 oraz Ron 1045, KRAM M-1936, leg. P. Janik \& A. Ronikier) zostały znalezione 9 maja 2020 r. przy topniejącym śniegu, na mchach i drobnych gałązkach świerkowych leżących na ziemi. Znalezione okazy $T$. sordida stanowią pierwsze notowania tego gatunku na terenie Polski, jak również w Karpatach.

Tatrzańskie okazy Trichia sordida mają wszystkie typowe cechy gatunku (PouLAIN i in. 2011). Tworzą skupienia siedzących zarodni wolnych i pierwoszczowocni o wymiarach 1,2-3,1 mm długości i 1,04-1,5 mm wysokości. Zarodnie pokryte są żółto-ochrową

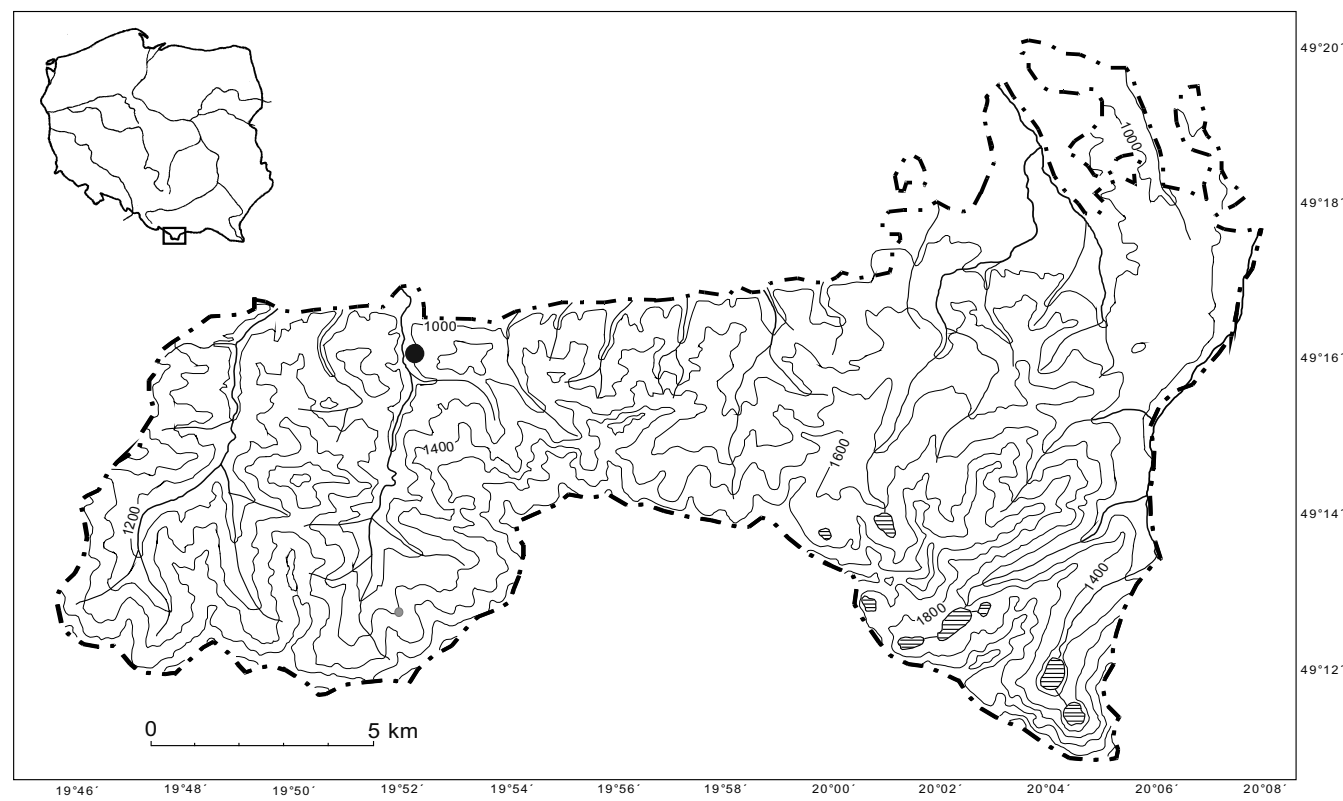

Ryc. 1. Lokalizacja nowego stanowiska Trichia sordida w Tatrach polskich

Fig. 1. New locality of Trichia sordida in the Polish Tatra Mts 

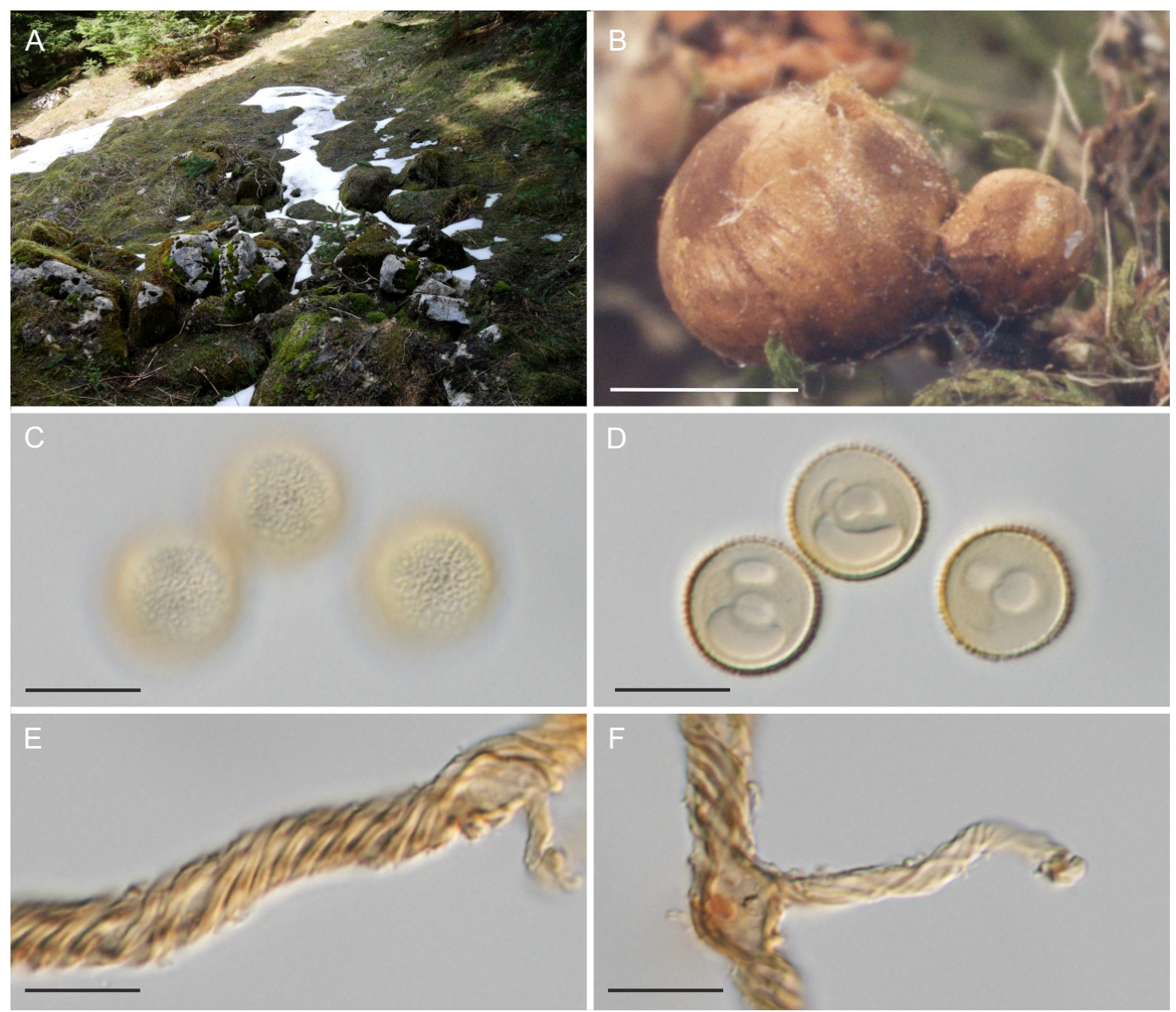

Ryc. 2. Trichia sordida na stanowisku w Tatrach. A. Stanowisko gatunku w Tatrach. B. Siedzące zarodnie z widocznymi ciemniejszymi plamami i smugami na powierzchni ściany zarodni. C-D. Zarodniki. E-F. Fragmenty sprężyc z charakterystycznymi spiralnie ułożonymi wężownicami i krótkimi bocznymi odgałęzieniami. Skala: B - $1 \mathrm{~mm}, \mathrm{C}-\mathrm{F}-10 \mu \mathrm{m}$. B-F: okaz Ron 1031

Fig. 2. Trichia sordida at the locality in the Tatra Mts. A. Locality of the species. B. Sessile sporophores with darker spots and stripes on peridium surface. C-D. Spores. E-F. Fragments of elaters with characteristic spiral bands and short side-branches. Scale bar: B - $1 \mathrm{~mm}, \mathrm{C}-\mathrm{F}-10 \mu \mathrm{m}$. B-F: collection Ron 1031

ścianą, na której powierzchni widoczne są ciemniejsze plamy i smugi (Ryc. 2B). Zarodniki o wymiarach 12-14,5 $\mu$ m są żółte i gęsto pokryte drobnymi brodawkami (Ryc. 2C-D). Włośnia ma postać wolnych nici, tworzącą wiele rozgałęzień i krótkich bocznych odgałęzień (Ryc. 2E-F).

Omawiany gatunek można łatwo odróżnić od innych przyśnieżnych gatunków z rodzaju Trichia. Trichia alpina tworzy zarodnie i pierwoszczowocnie o czarnej ścianie zarodni, która kontrastuje z jaskrawożółtą barwą włośni i masy zarodników. Z kolei T. nivicola makroskopowo jest nieco bardziej podobna do T. sordida, ponieważ jej ściana zarodni jest również dwukolorowa, jednak charakteryzuje się bardziej delikatną włośnią, której nici są nierozgałęzione i nie tworzą bocznych odgałęzień oraz mają krótsze zakończenia. 
Nowe znalezisko prezentowanego w niniejszej pracy gatunku wzbogaca różnorodność gatunkową śluzowców Polski o kolejny takson. Masyw tatrzański stanowi teren o dogodnych warunkach środowiskowych do rozwoju śluzowców przyśnieżnych. Odnotowanie gatunku rzadkiego, również w skali Europy, może wskazywać na potencjalne bogactwo gatunkowe tego obszaru. Różnorodna taksonomicznie grupa śluzowców przyśnieżnych jest równocześnie jedną z najsłabiej poznanych grup organizmów na terenie Tatr i odkrycie pełnej różnorodności tej grupy wymaga szczegółowych badań inwentaryzacyjnych.

Podziękowania. Praca została sfinansowana ze środków subwencyjnych przyznanych przez MNiSW dla Instytutu Botaniki im. W. Szafera Polskiej Akademii Nauk.

Summary. Trichia sordida (Trichiaceae), a nivicolous myxomycete new for Poland and the Carpathians, found in the Tatra Mts. Trichia sordida Johannesen represents the ecological guild of nivicolous myxomycetes, which occurs in mountainous areas at the edge of melting winter snow cover. It is not very common in the Northern Hemisphere and has never been reported from Poland. In the spring of 2020, two specimens of it were found in the Tatra Mts, in spruce forest close to the Polana Upłaz meadow on the Ciemniak massif $\left(49^{\circ} 15^{\prime} 05.0^{\prime \prime} \mathrm{N}, 1^{\circ} 52^{\prime} 46.4^{\prime \prime} \mathrm{E}\right.$; Figs 1,2$)$. Together with the newly reported species the list of nivicolous myxomycetes reported from the Tatra Mts numbers eleven species. Trichia sordida is also reported for the first time for the entire Carpathian range.

\section{LITERATURA}

Adl S. M., Bass D., Lane C. E., Lukeš J., Schoch C. L., Smirnov A., Agatha S., Berney C., Brown M. W., Burki F., Cárdenas P., ČepičKa I., Chistyakova L., CAmpo J., Dunthorn M., EdvardSen B., Eglit Y., Guillou L., Hampl V., Heiss A. A., Hoppenrath M., James T.Y., Karnowska A., Karpov S., Kim E., Kolisko M., Kudryavtsev A., Lahr D. J. G., Lara E., Le Gall L., Lynn D. H., Mann D. G., Massana R., Mitchell E. A. D., Morrow C., Park J. S., Pawlowski J. W., Powell M. J., Richter D. J., Rueckert S., Shadwick L., Shimano S., Spiegel F. W., Torruella G., Youssef N., Zlatogursky V. \& Zhang Q. 2019. Revisions to the classification, nomenclature, and diversity of eukaryotes. - Journal of Eukaryotic Microbiology 66: 4-119.

BochyneK A. \& DrozDowicz A. 2012. Biota śluzowców (Myxomycetes) lasu użytkowanego gospodarczo w okolicy przysiółka Wyrchczadeczka (Beskid Śląski). - Sylwan 156(1): 57-63.

Drozdowicz A. 1988. Nowe dla Polski gatunki śluzowców związanych z topniejącym śniegiem. - Folia Scientarum Lublinensis 30 (Biologia 1-2): 31-33.

Drozdowicz A. 1995. Myxomycetes of melting snow banks in Polish mountains. - W: XII Congress of European Mycologists, 3-7 September 1995. Abstracts, s. 18-19. Wageningen, the Netherlands.

Drozdowicz A., Ronikier A., Stojanowska W. \& Panek E. 2003. Myxomycetes of Poland. A checklist. - W: Z. Mirek (red.), Biodiversity of Poland. 10, s. 103. W. Szafer Institute of Botany, Polish Academy of Sciences, Kraków.

Everhart S. E. \& KelLer H. W. 2008. Life history strategies of corticolous myxomycetes: the life cycle, plasmodial types, fruiting bodies, and taxonomic orders. - Fungal Diversity 29: 1-16.

Illana C., Moreno G. \& Castillo A. 1993. Spanish Myxomycetes. VIII. Some nivicolous Myxomycetes from central Spain. - Cryptogamie, Mycologie 14(4): 241-253.

JANIK P. \& RonikieR A. 2016. Meriderma species (Myxomycetes) from the Polish Carpathians: a taxonomic revision using SEM-visualized spore ornamentation. - Acta Societatis Botanicorum Poloniae 85(1): 3492 . 
JohanNESEN E. W. 1984. A new species of Trichia (Myxomycetes) from Norway. - Mycotaxon 20(1): $81-84$.

Keller H. W., Everhart S. E. \& Kilgore C. M. 2017. The Myxomycetes: introduction, basic biology, life cycles, genetics, and reproduction. - W: S. STEPHENson \& C. ROJAS (red.), Myxomycetes. Biology, systematics, biogeography and ecology, s. 1-40. Academic Press, Cambridge.

Komorowska H. \& Drozdowicz A. 1996. Śluzowce - W: Z. Mirek, Z. GŁowaciński, K. KlimeK \& H. PięKoś-Mirkowa (red.), Przyroda Tatrzańskiego Parku Narodowego, s. 405-412. Tatrzański Park Narodowy, Zakopane - Kraków.

Kunnt A. 2006. Nivicole Myxomyceten aus Deutschland (unter besondere Berücksichtigung der bayerischen Alpen). Teil II. - Zeitschrift für Mykologie 72: 101-113.

Kunnt A. 2019. Bemerkenswerte Myxomycetenfunde: neue Arten, Neukombinationen und Nachweise seltener Arten, Teil 2. - Brichte der Bayerischer Botanischen Gesellschaft 89: 139-222.

LAdo C. \& Ronikier A. 2008. Nivicolous myxomycetes from the Pyrenees - notes on taxonomy and species diversity 1. Physarales and Trichiales. - Nova Hedwigia 87: 337-360.

Lado C., Ronikier A., Ronikier M. \& Drozdowicz A. 2005. Nivicolous myxomycetes from Sierra de Gredos (central Spain). - Nova Hedwigia 81: 371-394.

LiU Q.-S., YAN S.-Z. \& CHEN S.-L. 2015. Species diversity of myxomycetes associated with different terrestrial ecosystems, substrata (microhabitats) and environmental factors. - Mycological Progress 14: 27.

Martin G. W. \& Alexopoulos C. J. 1969. The Myxomycetes. s. 566. University of Iowa City, Iowa City.

MeYer M. 2010. Les myxomycetès nivicoles de notre région. - Bulletin mycologique et botanique Dauphiné-Savoie 197: 75-83.

MeYLan CH. 1921. Contribution à la connaissance des myxomycètes de la Suisse. - Bulletin de la Société Vaudoise des Sciences Naturelles 53(199): 451-463.

Poulain M., Meyer M. \& Bozonnet J. 2011. Les Myxomycètes. 1, 2. s. $568+544$ pl. Fédération mycologique et botanique Dauphiné-Savoie, Sevrier, France.

Ronikier A. \& HALAMSKi A. T. 2018. Is Myxomycetes (Amoebozoa) a truly ambiregnal group? A major issue in protist nomenclature. - Protist 169: 484-493.

Ronikier A., Ronikier M. \& Drozdowicz A. 2008. Diversity of nivicolous myxomycetes in the Gorce mountains - a low-elevation massif of the Western Carpathians. - Mycotaxon 103: 337-352.

Ronikier A., García-Cunchillos I., Janik P. \& Lado C. 2020. Nivicolous Trichiales from the austral Andes: unexpected diversity including two new species. - Mycologia 112(4): 753-780.

Ronikier A., Lado C., Meyer M. \& Wrigley De Basanta D. 2010. Two new species of nivicolous Lamproderma (Myxomycetes) from the mountains of Europe and America. - Mycologia 102(3): 718-728.

Sánchez A., Illana C. \& Moreno G. 1997. Nuevos datos sobre Myxomycetes nivícolas del Sistema Central. - W: XII Simposi de Botànica Criptogàmic (libro de resúmenes), s. 155-156. Valencia.

SÁnchez A., Moreno G., Illana C. \& Singer H. 2002. A study of nivicolous myxomycetes in southern Europe, Sierra de Guadarrama, Spain. - Persoonia 18(1): 71-84.

Singer H., Moreno G., Illana C. \& Kirchmair M. 2001. Nivicolous myxomycetes from Tyrol (Austria). I. - Cryptogamie, Mycologie 22(2): 79-94.

AnNa Ronikier i PaUlina Janik, Instytut Botaniki im. W. Szafera Polskiej Akademii Nauk, ul.Lubicz.46,31-512 Kraków,Polska; e-mail: a.ronikier@botany.pl,p.janik@botany.pl

Wptynęto: 30.10 .2020 r.; przyjęto do druku: $30.12 .2020 \mathrm{r}$.

DOI: https://doi.org/10.35535/ffgp-2020-0021 